\title{
RELATION BETWEEN MAXIMAL ANAEROBIC POWER OUTPUT AND TESTS ON ROWING ERGOMETER
}

\author{
Matej Šmída, Michal Clementis, Dušan Hamar, Yvetta Macejková \\ Department of Outdoor Sports and Swimming, Department of Sport Kinantropology, Faculty of Physical \\ Education and Sport, Comenius University in Bratislava
}

\begin{abstract}
Summary: Aim of this study was to compare relation between maximal anaerobic power output and $2,000 \mathrm{~m}$ test on rowing ergometer and relation between $6,000 \mathrm{~m}$ test and 2,000 $\mathrm{m}$ on rowing ergometer. It can be assumed that 2,000 m performance on rowing ergometer will significantly correlate with maximal anaerobic power output and 6,000 m performance. A group of 9 welltrained rowers (age: 18.3 years \pm 2.8 years, sport age: 4.9 years \pm 3.7 years, weight: $78.9 \mathrm{~kg} \pm 12.2$ $\mathrm{kg}$, height: $182.3 \mathrm{~cm} \pm 7.6 \mathrm{~cm}$ ) performed three tests in 1 week to determine maximal anaerobic power, $6,000 \mathrm{~m}$ and 2,000 m performance on Concept 2 model $\mathrm{D}$ rowing ergometer. A value of simple maximal stroke out of 10 -second all-out test with drag factor set to 200 was taken as a measure of maximal anaerobic power. Drag factor for $6,000 \mathrm{~m}$ and $2,000 \mathrm{~m}$ test was set individually. Average power during these tests was record. Research showed that both maximal anaerobic power and $6,000 \mathrm{~m}$ test correlated with $2,000 \mathrm{~m}$ test on rowing ergometer significantly $\left(r_{\text {map }}=0.93 p<0.01, r_{6 k}=0.95 p<0.01\right)$. Maximal anaerobic power and $6,000 \mathrm{~m}$ tests seem to be good predictors for 2,000 $\mathrm{m}$ score on rowing ergometer. However, maximal anaerobic power test can be used to monitor rowing performance during specific training cycle instead of longer and more demanding $6,000 \mathrm{~m}$ test.
\end{abstract}

Key words: rowing, maximal anaerobic power, ergometer

DOI 10.1515/afepuc-2017-0007

(C) Acta Facultatis Educationis Physicae Universitatis Comenianae 


\section{Introduction}

Rowing is a strength endurance sport which is performed by cyclic form of movement. Rowing competitions are held mostly on 2000-meter racecourse which is also length of Olympic race. In average, boat speed can reach $5.5 \mathrm{~m} \cdot \mathrm{s}^{-1}$ depending on boat class. Duration of race is from 5 min $40 \mathrm{~s}$ to 9 min with $200-250$ total strokes depending on category. Stroke rate is individual, relates to maturity and performance level of crews and is from 30 to 48 strokes per minute (Schickhofer 2010). According to Steinacker (1993) power per stroke in an elite men's eight averages 450 to $550 \mathrm{~W}$, but can be as high as $1,200 \mathrm{~W}$.

Energy for moving the boat during the race comes from aerobic and anaerobic energy systems. Many studies on elite male rowers suggest that average 2,000 $\mathrm{m}$ race is covered to $80-85 \%$ by aerobic and $20-15 \%$ by anaerobic energy. Maximal aerobic power $\left(\mathrm{VO}_{2} \mathrm{max}\right)$ is one of the most commonly measured physiological variables. It is the best measure of the functional limits of the cardiorespiratory system and is often used as measure of physical fitness. $\mathrm{VO}_{2} \max$ is the variable most often correlated to rowing performance (Ingham et al. 2002; Reichman et al. 2002). Maximal aerobic power can be estimated as the average power output from a $6,000 \mathrm{~m}$ test because of its duration (approximately 20 minutes). Anaerobic capabilities are particularly important off the start and in the final $250 \mathrm{~m}$ of the race. A single parameter of anaerobic ability is maximal anaerobic power. It can be measured as the maximum power of a single maximal stroke out of 10-second all-out test with the ergometer set to drag factor 200. Maximal anaerobic power has started to emerge as a strong predictor of rowing performance. Nolte (2011) showed that even though power at $\mathrm{VO}_{2}$ max was considered the best predictor of rowing performance, maximal anaerobic power on a rowing ergometer was highly correlated to on water rowing performance than $\mathrm{VO}_{2}$ max measured on a rowing ergometer. Similar results have been demonstrated on a group of female rowers where maximal anaerobic power correlated with $2 \mathrm{~km}$ ergometer time $(\mathrm{r}=0.87)$. Also changes in maximal anaerobic power were significantly correlated to changes in $2 \mathrm{~km}$ ergometer performance (Reichman et al. 2002).

Muscle fibres can be divided into two categories. Slow-twitch (ST) fibres and fasttwitch fibres, which can be subdivided into three categories - fast-twitch glycolytic (FT), fast-twitch oxidative glycolytic (FOG) and undifferentiated fast-twitch fibres (FTc) (Nolte 2011). Fibre-type studies have shown that rowers' muscles are composed of $70-85 \%$ ST 
fibres. In addition elite rowers ST fibres are hypertrophied and there is no significant difference between the cross-sectional areas of FT and ST fibres (Hagerman \& Staron 1983; Larsson \& Forsberg 1980; Roth et al. 1993; Steinacker 1993). This is something that is unique to rowers. Generally FT fibres are larger than ST fibres. Typical of many rowing programs is high volume of low- to moderate-rate rowing which can cause hypertrophy of ST fibres of rowers. Only $4-9 \%$ of the fibres are of the FT type in both international and national level rowers. The skeletal muscle of rowers is composed largely of ST and FOG muscle fibres (Nolte 2011). Low ratio of FT type fibres which was observed in successful rowers by more authors (Hagerman \& Staron 1983; Larsson \& Forsberg 1980; Roth et al. 1993; Steinacker 1993) might be affected by duration of active rowing career. Nevertheless, the knowledge of physiology, it is known that long-term preparation is not affecting the ratio of muscle fibres. This means that successful rowers are limited by genetic proportion of muscle fibres.

Theoretically, there would be difference in maximal power output between two rowers with same 2,000 m score but different sport age. It can be assumed that rower with less experience would have higher maximal anaerobic power output because it depends on number of FT type fibres.

Rowing represents unique sport requiring high levels of both strength and aerobic power. According to Nolte (2011) typical maximal anaerobic power scores for heavyweight men -900 to $1,100 \mathrm{~W}$ and lightweight men -650 to $800 \mathrm{~W}$. Average power output during 2,000 m test should be 40 to $45 \%$ of peak power. According to Steinacker (1993) forces of 1,000-1,500 $\mathrm{N}$ are needed in the start of the race, $600-800 \mathrm{~N}$ in the start phase, $500-700 \mathrm{~N}$ during the race, and $600-700 \mathrm{~N}$ for the finish (Figure 1). These data indicate that rowers need a high level of maximal strength and strength endurance.

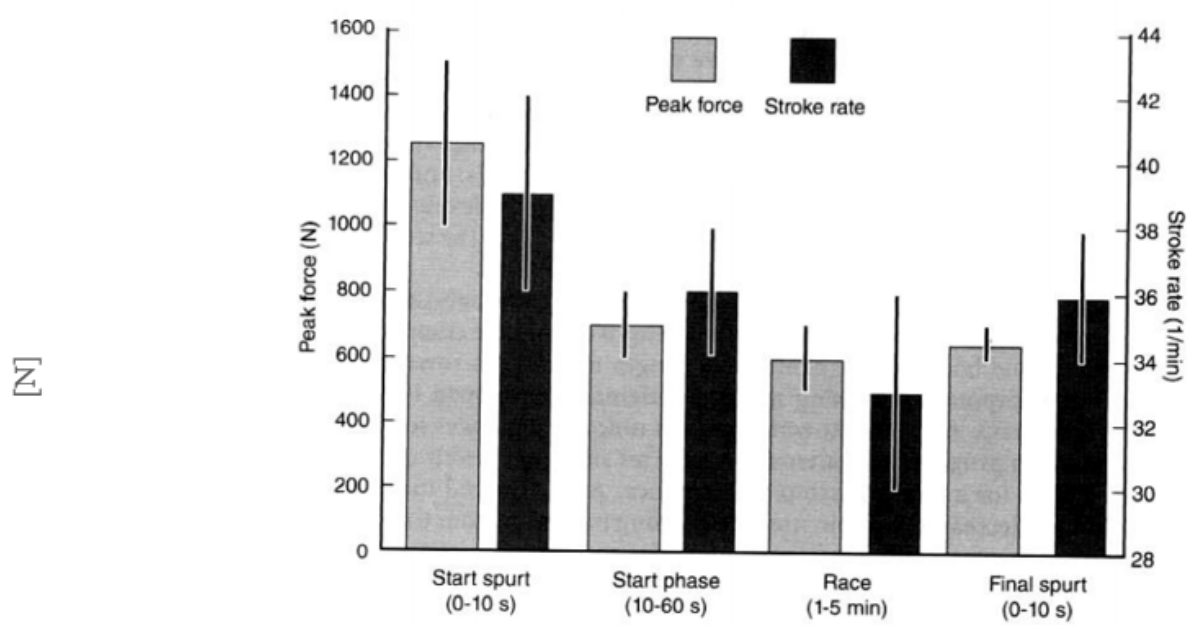




\section{Figure 1}

Peak force and stroke rate during 2,000 m race (Steinacker, 1993)

According to Hagerman \& Staron (1983) and Larsson \& Forsberg (1980) force production of rowers is pronounced namely at low velocities. This may be due to the large percentage of slow-twitch fibres found in competitive rowers. Earlier studies by Hagerman et al. (1978) and Roth et al. (1983) have shown lower reliance on aerobic metabolism during racing. Aerobic demand was about $67-70 \%$ of the typical 2,000 m race. However, $\mathrm{VO}_{2}$ max in rowers increased by $12 \%$ since 1980 and the amount of training dedicated to anaerobic exercise decreased from 23 to 7 hours per month (Fikerstrand \& Seiler 2004). Nevertheless, many coaches still rely on endless hours of aerobic training. They forget the importance of higher intensity anaerobic training, which can make the difference between winning and losing race. Therefore, the aim of this study was to elucidate relation between maximal anaerobic power output, 6,000 $\mathrm{m}$ and 2,000 $\mathrm{m}$ rowing performance on a group of well-trained rowers.

\section{Aim}

Aim of this study was to compare relation between maximal anaerobic power output and 2,000 m test on rowing ergometer and relation between 6,000 m test and 2,000 $\mathrm{m}$ on rowing ergometer.

\section{Methods}

A group of 9 well-trained rowers (age: 18.3 years \pm 2.8 years, sport age: 4.9 years \pm 3.7 years, weight: $78.9 \mathrm{~kg} \pm 12.2 \mathrm{~kg}$, height: $182.3 \mathrm{~cm} \pm 7.6 \mathrm{~cm}$ ) performed three tests on rowing ergometer Concept 2 model $\mathrm{D}$ to determine maximum anaerobic power (10-second all-out test), average power at 6.000 meter performance and average power at 2,000 meter performance.

Maximum anaerobic power was measured by means of a 10-second all-out ergometer test. On a Concept II model D, rowers did warm-up by rowing easy for 10 minutes (intensity $40 \% \mathrm{VO}_{2} \max$ ) (normal drag factor). At the end of warm up rowers came to a full stop, let the fly wheel stop and set the drag factor to 200. High drag factor is necessary to provide adequate resistance so that rowers can produce a true maximal anaerobic power. Lower drag factors do not exert enough resistance and rowers generate lower power. From a stopped flywheel rowers started to row as hard and as fast as possible 
for 10 seconds. A value of single maximal stroke out of 10-second all-out test was taken as a measure of maximal anaerobic power. Rowers did not use race start, but from first stroke they rode full slide. Then rested for 5 minutes with easy rowing (intensity $40 \% \mathrm{VO}_{2} \max$ ) and repeated 10-second test again. The best attempt of two was recorded. In all group it was second attempt, because of learning effect, which described McNeely (2009).

Group of rowers did this maximum anaerobic power test in warm up before competition in 2,000 meters. Like normally, rowers set their drag factor individually. It is not necessary to put high drag factor, because strokes cannot be so strong, because of lasting of tests. It is not possible to produce so high strength strokes for more than 6 minutes, what is normally time for 2,000 meter test. Mean power of 2,000 meter was captured.

6,000 $\mathrm{m}$ test was performed one week after maximal anaerobic test and 2,000 $\mathrm{m}$ test as part of Slovak National Rowing Federation winter trials. Drag factor was set individually as in 2,000 $\mathrm{m}$ test. Mean power of 6,000 $\mathrm{m}$ was captured.

\section{Statistical analysis}

To estimate relationship between maximum anaerobic power output and 2,000 m test and between $6,000 \mathrm{~m}$ test and 2,000 $\mathrm{m}$ test on rowing ergometer was applied nonparametric Spearman's rank correlation. The significance level was set to $\mathrm{p}<0.01$.

\section{Results and discussion}

Data obtained (Figure 2) demonstrated significant correlation $(\mathrm{r}=0.93 \mathrm{p}<0.01)$ between maximal anaerobic power output and mean power output at 2,000 m simulated race (Figure 3). There was significant correlation $(\mathrm{r}=0.95 \mathrm{p}<0.01)$ also between mean power output at 6,000 $\mathrm{m}$ and 2,000 $\mathrm{m}$ simulated race (Figure 4). 


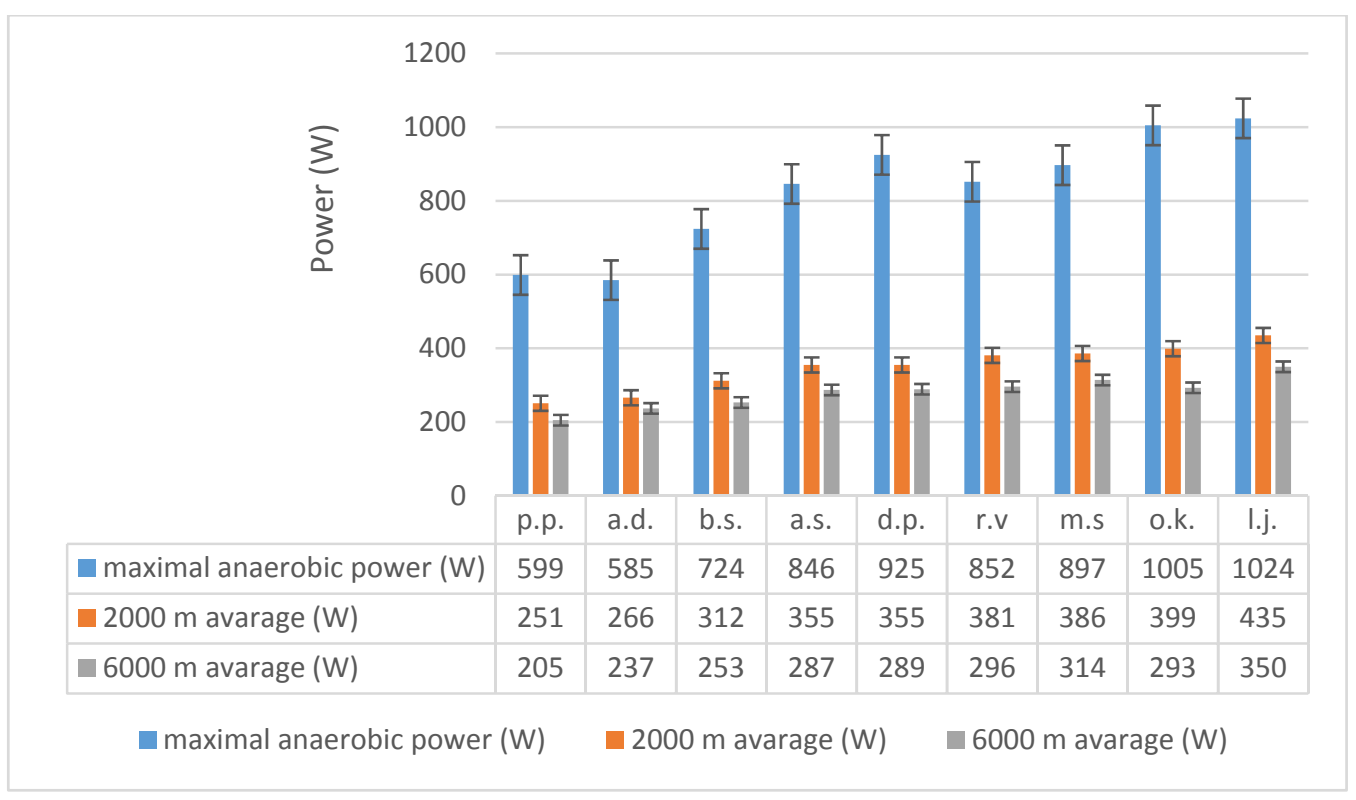

Figure 2

Data obtained by the measurements

These results are in accordance with interpretation of maximal anaerobic power test as predictor for 2,000 m result (Bourdin et al. 2004). However, they demonstrated in study of 54 highly trained rowers that maximal anaerobic power test $(\mathrm{r}=0.92)$ is better predictor than $\mathrm{VO}_{2} \max (\mathrm{r}=0.84)$. We found similar correlation $(\mathrm{r}=0.93)$ between maximal anaerobic power output and 2,000 $\mathrm{m}$ test but a little higher correlation $(\mathrm{r}=0.95)$ between $6,000 \mathrm{~m}$ and 2,000 $\mathrm{m}$ tests. Nevertheless, our study might be limited by number of participants. Traditionally, many coaches use longer and more exhaustive tests to predict improvement in rowing performance such as 5,000 $\mathrm{m}$ test and 6,000 $\mathrm{m}$ test which represent $\mathrm{VO}_{2} \max$ level. Anyway, these results show that anaerobic part of performance is as important as aerobic part and it can be anaerobic part that makes the difference in rowers and crews whose aerobic fitness level is equal (Nolte 2011).

The case may be the role of individuality, when one proband may achieve high performance in maximal anaerobic test and low performance in $6,000 \mathrm{~m}$ and the other way round. In future, it would be interesting to see the impact of power or endurance training on one or the other type of rowers.

It would be interesting if further research would contain larger group of rowers to get more accurate results. This would provide better comparison of tests with same research sample and same equipment. Other research could observe correlation between 2,000-meter test and maximal power output through year-long training cycle because there is difference in volume of strength training during single periods of training cycle. 
We don't recommend to use maximal anaerobic power test as predictor of $2,000 \mathrm{~m}$ performance or adaptation to specific training cycle for beginners. The hypertrophy of ST type fibres and lower adaptability of FT type fibres can occur because of adaptation to rowing training which can distort results of maximal anaerobic power test.

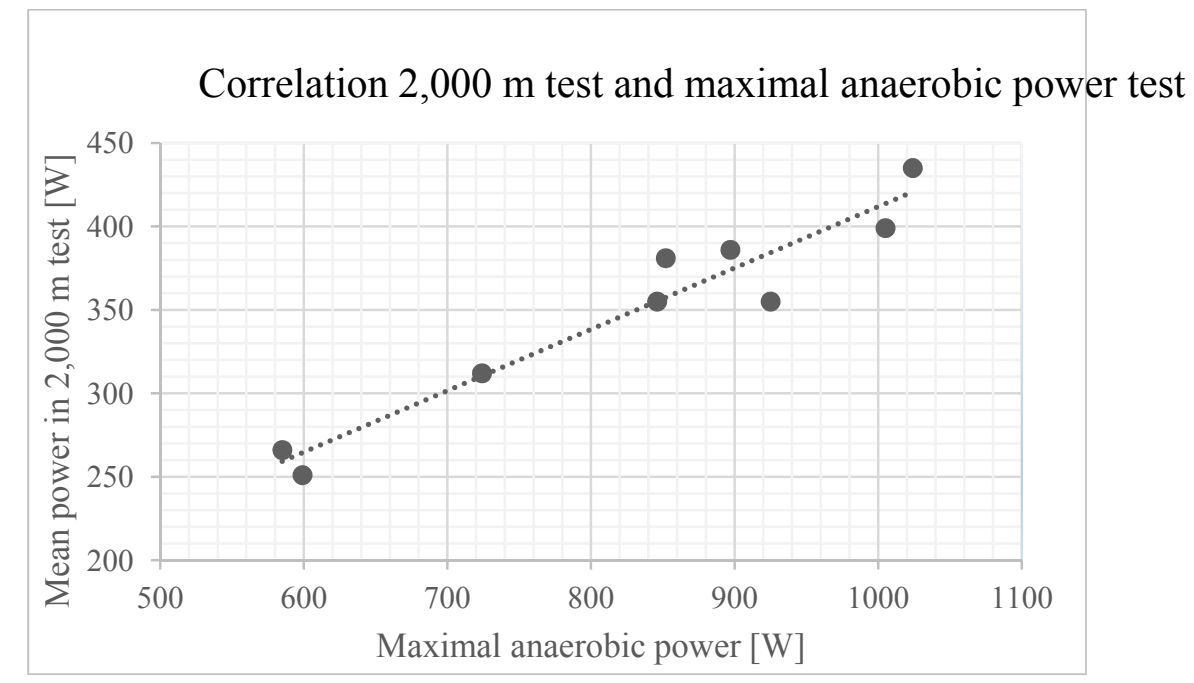

Figure 3

Correlation between 2,000 $\mathrm{m}$ test and maximal anaerobic $10 \mathrm{~s}$ all-out test

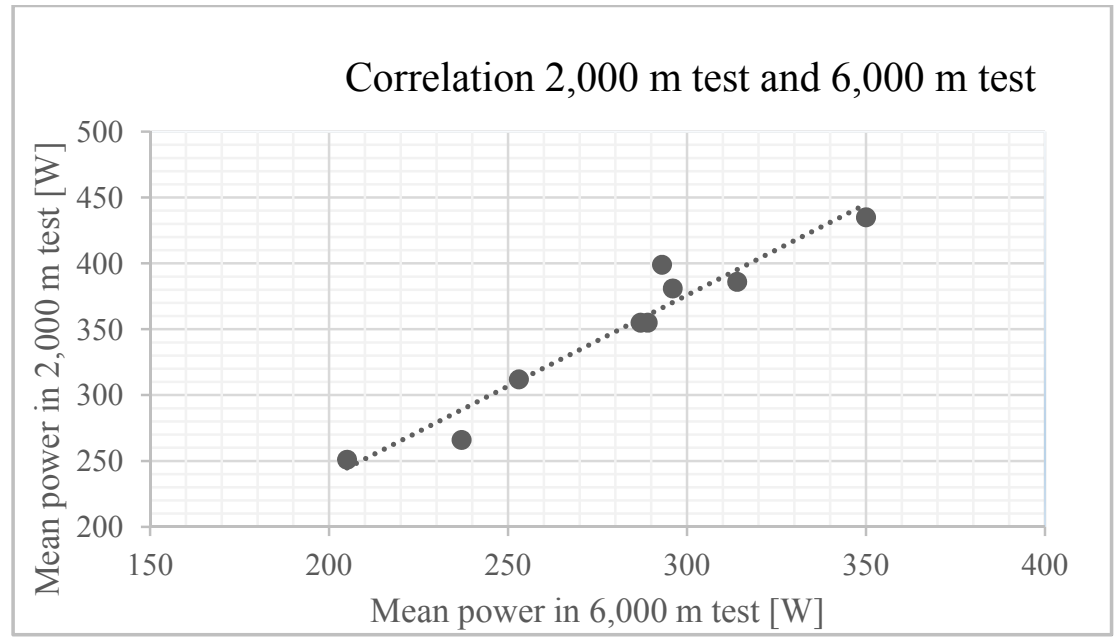

Figure 4

Correlation between 6,000 $\mathrm{m}$ test and 2,000 $\mathrm{m}$ test

\section{Conclusion}

There was highly significant correlation between maximal anaerobic power test and $2,000 \mathrm{~m}$ test $(\mathrm{r}=0.93 ; \mathrm{p}<0.01)$ and between $6,000 \mathrm{~m}$ test and $2,000 \mathrm{~m}$ test $(\mathrm{r}=0.95 \mathrm{p}<$ 0.01). High correlation in both cases confirmed use of both tests as predictors of $2,000 \mathrm{~m}$ 
rowing ergometer performance. However, we recommend to use maximal anaerobic power output test because of its shorter duration and lower energy demands.

\section{References}

1. BOURDIN, M. et al., 2004. Peak power output predicts rowing ergometer performance in elite male rowers. International journal of sports medicine. 25: 368-373.

2. FIKERSTRAND, A. \& K. SEILER, 2004. Training and performance characteristics among Norwegian international rowers from 1970 - 2001. Scandinavian Journal of Medicine and Science in Sports. 14: 303-310.

3. INGHAM, S. A., G. P. WHYTE, K. JONES et al., 2002. Determinants of 2,000 m rowing ergometer performance in elite rowers. European Journal of Applied Physiology. 88: 243-246.

4. HAGERMAN, F. C., M. C. CONNORS, G. R. GAUlT \& W. J. POLINSKI, 1978. Energy expenditure during simulated rowing. Journal of Applied Physiology. 45: 8793.

5. HAGERMAN, F. C. \& R. S. STARON, 1983. Seasonal variations among physiological variables in elite oarsmen. Canadian Journal of Applied Sport Sciences. 8: 143-183.

6. LARSSON, L. \& A. FORSBERG, 1980. Morphological muscle characteristics in rowers. Canadian Journal of Applied Sport Sciences. 5: 239-244.

7. MCNEELY, E., 2009. Peak Power: The limiting factor to rowing performance [Online] published 20.1.2009, The Peak Centre for Human Performance in Canada https://peakcentre.wordpress.com/2009/01/20/peak-power-the-limiting-factor-torowing-performance/

8. NOLTE, V., 2011. Rowing Faster, Second Edition. Human Kinetics, pp. 71-78 and $163-167$.

9. REICHMAN, S., R. ZOELLER, G. BALASEKARAN, F. GOSS \& R. ROBERTSON, 2002. Prediction of $2,000 \mathrm{~m}$ indoor rowing performance using a $30 \mathrm{~s}$ sprint and maximal oxygen uptake. Journal of Sport Science. 20: 681-687.

10. ROTH, W., E. HASART, W. WOLF \& B. PANSOLD, 1983. Untersuchungen zur Dynamik der Energiebereitstellung während maximaler Mittelzeitausdauerbelastung. Medicine in Sport. 23: 107-114. 
11. ROTH, W., P. SCHWANITZ, P. PAS \& P. BAUER, 1993. Force-time characteristics of the rowing stroke and corresponding physiological muscle adaptations. International Journal of Sports Medicine. 14: 32-34.

12. SCHICKHOFER, P., 2010. Faktory podmieňujúce výkon na $2000 \mathrm{~m}$ na veslárskom trenažéri [Determining factors of 2,000 m performance on rowing ergometer]. Telesná výchova \& šport. 20(3): 25-27.

13. STEINACKER, J. M., 1993. Physiological aspects of training for rowing. International Journal of Sports Medicine. 14: 3-10. 